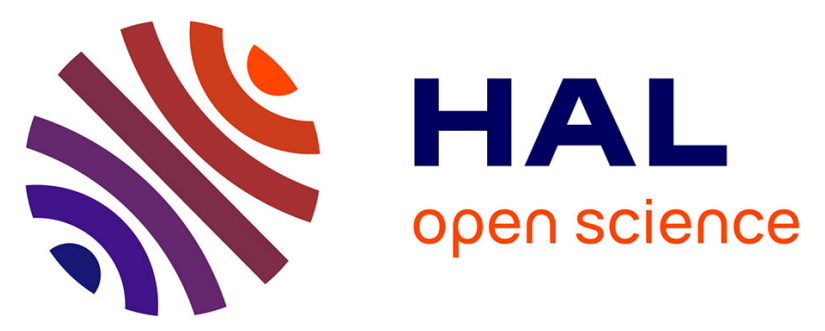

\title{
Who bears the burden of universal health coverage? An assessment of alternative financing policies using an overlapping-generations general equilibrium model
}

\author{
Mohammad Abu-Zaineh, Sameera Awawda, Bruno Ventelou
}

\section{- To cite this version:}

Mohammad Abu-Zaineh, Sameera Awawda, Bruno Ventelou. Who bears the burden of universal health coverage? An assessment of alternative financing policies using an overlapping-generations general equilibrium model. Health Policy and Planning, 2020, 35 (7), pp.867-877. 10.1093/heapol/czaa041 . hal-02877144

HAL Id: hal-02877144

https://hal-amu.archives-ouvertes.fr/hal-02877144

Submitted on 22 Jun 2020

HAL is a multi-disciplinary open access archive for the deposit and dissemination of scientific research documents, whether they are published or not. The documents may come from teaching and research institutions in France or abroad, or from public or private research centers.
L'archive ouverte pluridisciplinaire HAL, est destinée au dépôt et à la diffusion de documents scientifiques de niveau recherche, publiés ou non, émanant des établissements d'enseignement et de recherche français ou étrangers, des laboratoires publics ou privés. 


\title{
Who bears the burden of universal health coverage? An assessment of alternative financing policies using an overlapping-generations general equilibrium model
}

\author{
Mohammad Abu-Zaineh, Sameera Awawda* and Bruno Ventelou \\ Aix-Marseille University, CNRS, EHESS, Centrale Marseille, AMSE, and IDEP, 5 Boulevard Maurice Bourdet CS50498 F-13205 \\ Marseille Cedex 01, France \\ *Corresponding author. Aix-Marseille University, CNRS, EHESS, Centrale Marseille, AMSE, and IDEP, 5 Boulevard Maurice Bourdet \\ CS50498 F-13205 Marseille Cedex 01, France. E-mail: sameera.awawda@univ-amu.fr
}

Accepted on 7 April 2020

\begin{abstract}
In their quest for universal health coverage (UHC), many developing countries use alternative financing strategies including general revenues to expand health coverage to the whole popula-tion. Unless a policy adjustment is undertaken, future generations may foot the bill of the UHC. This raises the important policy questions of who bears the burden of UHC and whether the UHC-fiscal stance is sustainable in the long term. These two questions are addressed using an overlap-ping generations model within a general equilibrium (OLG-CGE) framework applied to Palestine. We assess and compare alternative ways of financing the UHC-ridden deficit (viz. deferred-debt, current and phased-manner finance) and their implications on fiscal sustainability and intergenera-tional inequalities. The policy instruments examined include direct labour-income tax and indirect consumption taxes as well as health insurance contributions. Results show that in the absence of any policy adjustment, the implementation of UHC would explode the fiscal deficit and debt-GDP ratio. This indicates that the UHC-fiscal stance is rather unsustainable in the long term, thus, calling for a policy adjustment to service the UHC debt. Among the policies we examined, a current rather than deferred-debt finance through consumption taxation emerged to be preferred over other policies in terms of its implications for both fiscal sustainability and intergenerational inequality.
\end{abstract}

Keywords: Universal health coverage, overlapping generations, computable general equilibrium, fiscal sustainability, intergenerational inequality

\section{Introduction}

The core function of 'universal health coverage' (UHC) is to spread the financial burden of healthcare across the broader population (risk-subsidies) (Dye et al., 2013). In their quest to reach UHC, many developing countries rely on general government revenues to expand health coverage to the whole population (Lagomarsino et al., 2012; Kutzin et al., 2016). Unless a fiscal consolidation policy is undertaken in the short-run, the parallel expansion of the coverage of both the population and healthcare costs may result in a sizeable budgetary deficit (Gottret and Schieber, 2006; Somanathan et al., 2014). Shifting the UHC-debt burden to future generations, with at the same time subsidizing the healthcare of the current aged-population, may exacerbate intergenerational inequality. This raises the important policy questions on whether the UHC-fiscal stance is sustainable and to what extent the UHC-oriented reforms would result in intergenerational transfer (i.e. who bears the burden of $U H C)$.

This article addresses the above questions using an overlappinggenerations in a computable general equilibrium (OLG-CGE) framework. This allows to measure intergenerational inequalities in a given country while accounting for its particular demographic changes as well as the general equilibrium effect on its agents' decisions over time. The OLG-CGE model is calibrated and applied to the occupied Palestinian territory $(\mathrm{oPt})$, using nationally representative micro and macro data. The main health insurance scheme in the 


\section{Key Messages}

- Universal health coverage (UHC) appears to be unsustainable in the long term in low health insurance coverage settings.

- The 'deferred-debt-finance' policies imply that UHC debt is repaid in the long term by future generations thus resulting in high intergenerational transfers.

- Policymakers may have to trade-off fiscal sustainability against intergenerational inequality in their way to achieve UHC.

oPt is the Government Health Insurance (GHI). The GHI covers the public sector employees on a mandatory basis while non-public sector employees can join on a voluntary basis (with a flat contribution rate of $5 \%$ of their basic monthly income) (World Bank, 2008). The little existing evidence on UHC suggests that the expansion of a publicly funded health insurance can have a confounding burden on government budget (Somanathan et al., 2014). Akin to other developing countries, given the budget constraints and the limited capacity to generate additional fiscal space in the oPt, the oPt government may have to consider alternative strategies to finance the expected additional health expenditures generated by UHC (Heller, 2006; WHO, 2017). Among these policies, current and phased-manner policy adjustment may be considered. These policies entail, respectively, paying the bill of UHC concurrently and gradually with its implementation. However, given the limited capacity of governments in the context of low-coverage and low-resource setting to raise additional revenues in the short term, some may argue in favour of a deferred-debt policy adjustment. The latter entails transferring the UHC-driven debt to future generations through, e.g. raising taxes or contributions.

We, therefore, assess and compare these alternative ways of financing the UHC debt and their implications for fiscal sustainability and intergenerational inequalities using microsimulation within the OLG-CGE model. The impact of fiscal consolidation policies on intergenerational inequality has been widely addressed in the literature, both theoretically and empirically. As in the domain of public deficit and debt, the magnitude of the intergenerational transfers will depend, among other things, on the respective size of the generations (i.e. the relative shares of the young vs the elderly) (Tovar and Urdinola, 2014), the contracted level of the debt (i.e. level of reimbursement rates), and of course the correlation between individuals' age and health status (Auerbach et al., 1994; Grundy, 2005), which are expected to be substantially different in developing countries compared with developed countries.

Empirical evidence shows that intergenerational inequality would depend on the type and timing of fiscal consolidation. For instance, Tokuoka (2012) shows that, in general, a delayed policy adjustment would increase the burden for young future generations while reducing that for current generations. Balassone et al. (2008) assessed the impact of different budgetary strategies on fiscal sustainability and intergenerational inequality in Europe while taking into account the increasing cost of population aging. Accordingly, an early tax adjustment may be preferred over phased-manner to avoid transferring the cost of aging population to future generations. Creedy and Guest (2008) analysed the implications of alternative tax regimes applying to private pensions for intergenerational inequality and social welfare. Their results suggested that tax exemption of all private pension benefits may increase intergenerational inequality among the older and younger workers.

Intergenerational inequality has been assessed by either comparing consumption or utility across generations (e.g. Creedy and
Guest, 2008; Guest, 2008; Andersen and Gestsson, 2016) or by using a summary measure of income inequality such as Gini index (e.g. Van Kippersluis et al., 2009). Unlike the common practice in the literature, this article proposes two simple measures to assess UHC-ridden intergenerational inequality at each time period, viz. the relative incremental burden (RIB) of UHC across generations (young vs elderly and current vs future). These are defined as the ratios of the net incremental burden borne by each generation in the post- and pre-policy adjustment.

Methods and results reported in this article can be useful to help inform policy design on the appropriate path towards implementing an equitable and sustainable UHC. The remaining of this article is organized as follows. The next section (Methods and materials section) presents the method, simulation scenarios and the datasets used in the analysis. Results: the impact of UHC on fiscal sustainability and intergenerational inequality section presents the results. Discussion section discusses the main findings and Conclusion section concludes.

\section{Methods and materials}

We apply an OLG model within a CGE framework (OLG-CGE) to investigate the potential impact of UHC reform on intergenerational inequalities in the oPt. The OLG-CGE allows taking into account the mutual influence between macro-units (aggregate economic implications) and micro-units (distributional effects) (Wickens, 2012). It also allows taking into account heterogeneity across individuals by disaggregating them according to a set of characteristics, which include amongst others, age, gender, employment status and socio-economic status. The model is first calibrated at the initial steady state (baseline equilibrium of 2015). We, then, apply different policy scenarios with the aim of assessing the impact of UHC on intergenerational inequalities and to find the optimal financing-mix that guarantee an equitable and sustainable UHC. The macroeconomic impact of UHC reform is, first, examined within the Sustainable Development Goals (SDGs) timespan (2015-30). The UHC impact on intergenerational inequality is then examined within a wider timespan following 2030.

\section{Model setup \\ Time and demographics}

The available demographic surveys provide information on the population structure by 5 -year age groups, starting with $0-4$ years and ending with 80 years and over. Thus, our OLG model involves three generations: (1) children and adolescents aging from 0 to 19 years $\left(J_{1}=4\right.$ cohorts), (2) young and adults aging from 20 to 59 years $\left(J_{2}=8\right.$ cohorts) and (3) the elderly ageing 60 years and above $\left(J_{3}=5\right.$ cohorts). We assume no child labour, children and adolescents totally depend on their parents. The influence of children and adolescents on the model is thus only captured through the 
value of their aggregate consumption expenditures which varies according to their relative size in the demographic profile. We further assume that the young supply labour and the elderly are retired. The construction of the working force cohorts is rather context specific. According to the different Palestinian national surveys, the minimum age of the head of the household, who is responsible for making decisions, is around 21-23 years old. We, therefore, assume that individuals younger than 20 years old belong to the cohorts of children and adolescents. As regards the retirement age, the average actual age of retirement is 60 years old.

We consider a discrete time model with a 5 -year period. At each period, a new cohort is born while elderly are allowed to live until the age of 84 and in-between groups become one period older. Each agent lives with uncertainty that is captured by the survival rate, $q$. The probability that an agent belonging to the $j^{\text {th }}$ age group $(j=1, \ldots, 17)$ survives to the next period (i.e. enter the $(j+1)$ th age group) is $q_{j+1}$, where $q_{>17}$ is zero. The size of each age group at time $t$ is denoted by $N_{j, t}$ where the total size of the population is $N_{t}=\sum_{j=1}^{17} N_{j, t}$. We employ the cohort-component method to project the population (Smith et al., 2006). This involves replicating the population at each time period according to the following Markov process. The size of each age group $j=2, \ldots, 17$ is calculated as $N_{j, t}=q_{j, t} N_{j-1, t-1}$. Since investment in health is expected to improve the survival rate (Halliday et al., 2019), we assume that the survival rate at period, $t, q_{j, t}=q_{j, t-1}\left(1+p_{j}\right)$ where $p_{j}$ is extrapolated based on historical census of the population (PCBS, 2010). The survival rate of the first period is calibrated on the baseline data such that $q_{j, 1}=\left(\eta_{j, t_{0}} / \eta_{j-1, t_{0}-1}\right)\left(1+n_{t_{0}}\right)$, where $\eta_{j, t_{0}}$ is the share of group $j$ in the population and $n_{t_{0}}$ is the population growth rate.

The size of the newborn cohort is $N_{1, t}=f \sum_{j=4}^{10} N_{j}^{\text {female }}$, where $f$ is the fertility rate-assumed to be constant-calculated as the size of the newborn cohort divided by the size of women in the reproductive age, and $N_{j}^{\text {female }}$ is the female size in age group $j$. The population growth rate at period $t$ is thus measured as $n_{t}=\left(N_{t} / N_{t-1}\right)-1$. Figure 1 shows the actual decomposition of the Palestinian population living in the West Bank and Gaza Strip at the baseline 2015 and the projections for each generation for the next 45 years. As shown, the share of the elderly, which is relatively small at the baseline would almost double by 2060 while the share of young would remain almost the same.

\section{Agents' preferences}

The young, belonging to cohort $J_{1}<j \leq J_{1}+J_{2}$, maximize their expected discounted utility along their life cycle. Each individual in group $j$ decides over a set of choices, $c_{j, t}^{y}=\left\{l_{j, t}, x_{j, t}, h_{j, t}, a_{j+1, t+1}\right\}$, where $l_{t}$ is labour supply, $x_{t}$ is consumption expenditure of nonhealth goods and services, $h_{t}$ is healthcare expenditure and $a_{t+1}$ is assets. The young earn labour income and pay income and consumption taxes, $\tau_{t}^{l}$ and $\tau_{t}^{c}$, in addition to health insurance premiums, $\pi_{t}$, and pension contributions, $\tau_{t}^{P h}$. The young programme is thus,

$$
\max _{c_{j, t}^{y}} E_{0} \sum_{t=t_{0}, j=j_{0}}^{T} \beta^{t} q_{j, t} U\left(x_{j, t}, h_{j, t}, l_{j, t}\right)
$$

subject to the resource constraint

$$
\begin{aligned}
& \left(1-\tau_{t}^{l}-\tau_{t}^{P h}-\left(1-\psi_{t}\right) \pi_{t}\right) w_{t} l_{j, t} \Gamma(5 \leq j \leq 12)+\left(1+r_{t}\right) a_{j, t} \\
& +\left(1-\pi_{t}\right) I P_{j, t} \Gamma(13 \leq j \leq 17)=\left(1+\tau_{t}^{c}\right)\left(x_{j, t}+x_{t}^{c} \Gamma(5 \leq j \leq 12)\right) \\
& +\left(1-\left(1-\kappa_{t}\right)\left(1-\mathrm{o}_{t}\right)\right)\left(h_{j, t}+h_{t}^{c} \Gamma(5 \leq j \leq 12)\right)+a_{j+1, t+1},
\end{aligned}
$$

where $\beta \in[0,1]$ is the time preference rate, $\psi_{t} \in[0,1]$ is the fraction of the health insurance premium paid by the employer, $\kappa_{t}$ is the copayment rate, $o_{t}$ is the out-of-pocket payments rate, $w_{t}$ is the wage rate, $r_{t}$ is the interest rate, $x_{t}^{c}$ and $h_{t}^{c}$ are the children expenditure on consumption of non-health goods and services and healthcare, respectively. The index function, $\Gamma(\cdot)$, takes one if the condition between parentheses is satisfied, zero otherwise. The specification chosen for the utility function, when $j \in\{5, \ldots, 12\}$, is

$$
U\left(l_{j, t}, x_{j, t}, h_{j, t}\right)=\log \left(x_{j, t}^{1-\alpha_{j}} h_{j, t}^{\alpha_{j}}-\mu_{j} l_{j, t}^{2}\right)
$$

where $\alpha_{j}$ is the expenditure shares of $h$ for group, $j$. Individuals gain disutility from labour, where $\mu_{j}$ is a labour distribution parameter

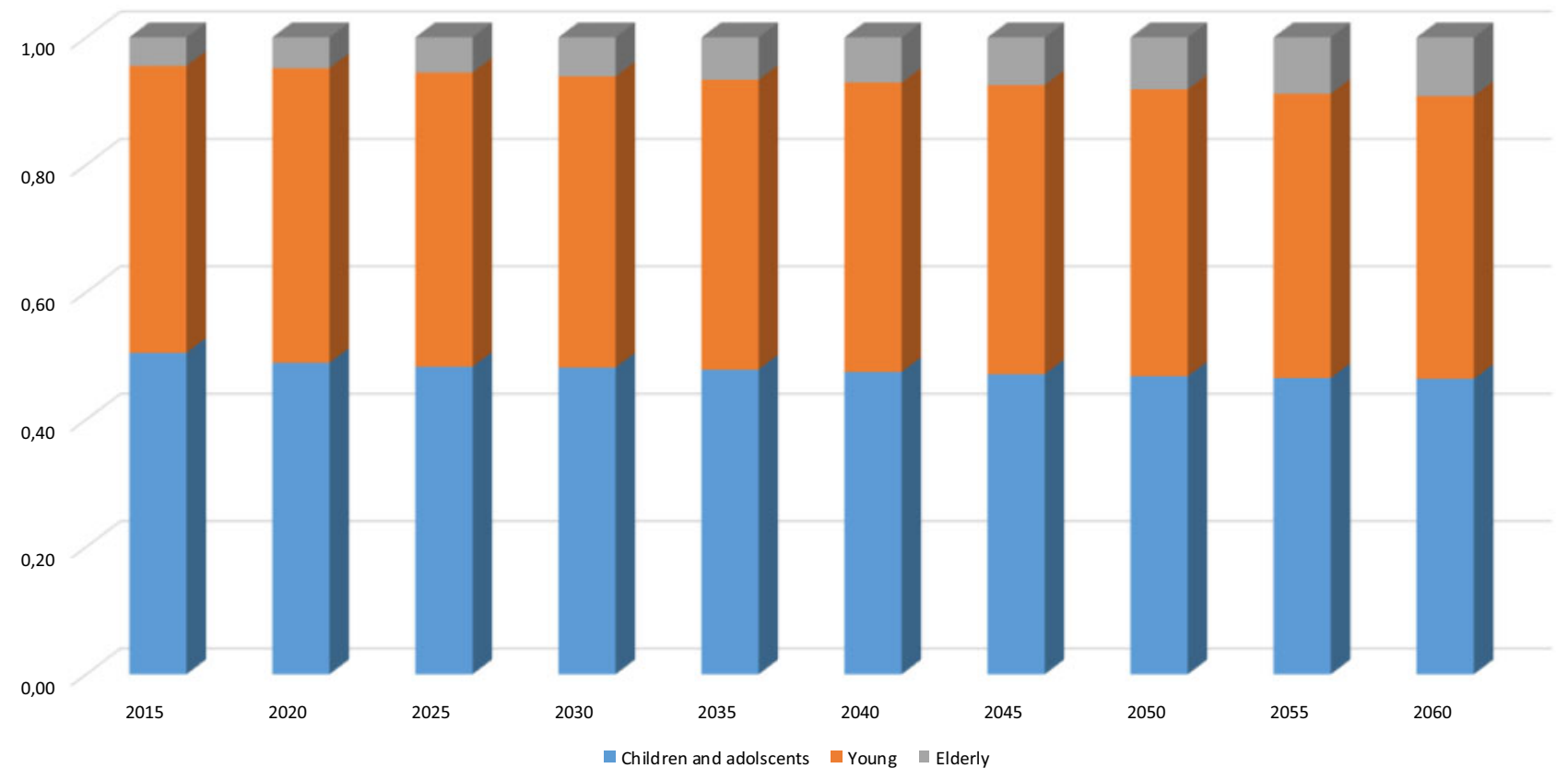

Figure 1 Projections of the Palestinain population in the West Bank and Gaza Strip 2015-60. 
measuring the relative weight of labour in the utility function. Unlike the common practice where $\mu$ is assumed to be constant (e.g. Auerbach and Kotlikoff, 1987; Bassetto, 2008), $\mu_{j}$ is calibrated here on the baseline data and is allowed to vary across age-gender groups. When become elderly, individuals receive retirement pension income, $I P_{j, t}=\left(\tau_{t}^{P h}+\tau_{t}^{P G}\right)\left(T^{l} / T^{r}\right) \overline{w_{t} l_{12, t}}$, where $\overline{w_{t} l_{12, t}}$ is the corresponding average labour income of the $12^{\text {th }}$ age group, $\tau_{t}^{P G}$ is the government contribution rate to the pension system, $T^{l}$ is the number of working years and $T^{r}$ is the number of years an individual is expected to live in retirement. The utility function corresponds to age group $j \in\{13, \ldots, 17\}$ is

$$
U\left(x_{j, t}, h_{j, t}\right)=\log x_{j, t}+v_{j} h_{j, t}+b_{j} h_{j, t}^{2},
$$

where $v_{j}>0$ captures the alleviation of sickness and $b_{j}<0$ captures the disutility of sickness related to aging. ${ }^{1}$ The elderly decide over the set $c_{j, t}^{o}=\left\{x_{j, t}, h_{j, t}, a_{j+1, t+1}\right\}$. Accordingly, their optimization problem is,

$$
\max _{c_{j, t}^{o}} E_{0} \sum_{t=t_{0}, j=13}^{T} \beta^{t} q_{j, t} U\left(x_{j, t}, h_{j, t}\right)
$$

subject to the resource constraint

$$
\begin{aligned}
\left(1+r_{t}\right) a_{j, t}+\left(1-\pi_{t}\right) I P_{j, t}= & \left(1+\tau_{t}^{c}\right) x_{j, t}+\left(1-\left(1-\kappa_{t}\right)\left(1-o_{t}\right)\right) h_{j, t} \\
& +a_{j+1, t+1} .
\end{aligned}
$$

The first-order conditions (FOCs) give, amongst others, the equations of intratemporal substitution between health and non-health consumption expenditures for young and elderly, respectively, as follows:

$$
\begin{aligned}
\frac{\left(1-\alpha_{j}\right) h_{j, t}}{\alpha_{j} x_{j, t}} & =\frac{\left(1+\tau_{t}^{c}\right)}{\left(1-\left(1-\kappa_{t}\right)\left(1-o_{t}\right)\right)} \\
\frac{\left(v_{j}+2 b_{j} h_{j, t}\right)}{x_{j, t}} & =\frac{\left(1+\tau_{t}^{c}\right)}{\left(1-\left(1-\kappa_{t}\right)\left(1-o_{t}\right)\right)} .
\end{aligned}
$$

These FOCs show how the substitution between health and nonhealth consumption expenditures differs between young and elderly. Equation (8) suggests that at the margin the elderly tends to have a subsistence level of health expenditure, that is equal to $-v_{j} /\left(2 b_{j}+1\right)>0$, to improve their well-being. By contrast, Eq. (7) indicates that the amount of health expenditures of the young may be equal to zero.

\subsubsection{Technology}

The production sector is represented by a single competitive firm that produces a single good with constant return to scale according to the following Cobb-Douglas function:

$$
Y_{t}=T_{t} K_{t}^{\gamma} L_{t}^{1-\gamma}
$$

The firm optimization problem is given by,

$$
\max _{K, L} T_{t} K_{t}^{\gamma} L_{t}^{1-\gamma}-\left[1+r_{t}+\tau_{t}^{k}+\delta_{t}\right] K_{t}-\left(1+\psi_{t} \pi_{t}\right) w_{t} L_{t}
$$

where $\tau_{t}^{k}$ is tax on capital, $K, L$ is total demand for labour, $\delta_{t}$ is the depreciation rate, $Y_{t}$ is aggregate output, $T_{t}$ is technology parameter and $\gamma$ is the shares of $K$ of total output. The set of inputs' prices $\left\{w_{t}, r_{t}\right\}$ of the competitive equilibrium at period $t$ is,

$\left\{w_{t}=\left[(1-\gamma) T_{t} K_{t}{ }^{\gamma} L_{t}{ }^{-\gamma}\right] /\left(1+\psi_{t} \pi_{t}\right), r_{t}=\gamma T_{t} K_{t}{ }^{\gamma-1} L_{t}{ }^{1-\gamma}-\left(1+\tau_{t}^{k}+\delta_{t}\right)\right\}$,

where capital accumulation is given by: $K_{t+1}=I_{t}+\left(1-\delta_{t}\right) K_{t}, I_{t}$ is aggregate investment.

\section{Government}

The government raises revenues, $R_{t}$, from proportional taxes on consumption, income, capital and labour, transfers from abroad, $\operatorname{Tr}_{t}^{G}$ and revenues of the health insurance account, $R_{t}^{H I}$. Thus,

$$
R_{t}=\tau_{t}^{c} C_{t}+\tau_{t}^{k} K_{t}+\left(\tau_{t}^{l}+\tau_{t}^{P h}\right) w_{t} L_{t}^{s}+\operatorname{Tr}_{t}^{G}+R_{t}^{H I},
$$

where $C_{t}$ is the aggregate consumption and $L_{t}^{s}$ is the aggregate labour supply. Government revenues from the insurance account are given by,

$$
\begin{aligned}
R_{t}^{H I} & =\sum_{j=5}^{17} N_{j, t}\left[\pi_{t} w_{t} \bar{l}_{j, t} \Gamma(5 \leq j \leq 12)+\pi_{t} I P_{j, t} \Gamma(13 \leq j \leq 17)\right. \\
& \left.+\left(1-\left(1-\kappa_{t}\right)\left(1-o_{t}\right)\right) \bar{h}_{j, t}\right]+\left(1-\left(1-\kappa_{t}\right)\left(1-o_{t}\right)\right) H_{t}^{c},
\end{aligned}
$$

where $\bar{h}_{j, t}$ is the average health expenditure of the $j^{\text {th }}$ age group and $H_{t}^{c}=\sum_{j=1}^{4} N_{j, t} \bar{h}_{t}^{c}$. Thus, $R_{t}^{H I}$ is total contributions paid as premiums from income in addition to the share of health expenditure paid as copayment and out-of-pocket payments. The government is assumed to be the single provider of healthcare. It spends on public consumption on non-health sectors, $C_{t}^{G}$, the UHC programme, $G_{t}^{H I}$ and the pension system, $P_{t}$. Total government expenditure $G$ is thus given by,

$$
G_{t}=C_{t}^{G}+G_{t}^{H I}+P_{t}
$$

where

$$
G_{t}^{H I}=\sum_{j=1}^{17} N_{j, t}\left(1-\kappa_{t}\right)\left(1-o_{t}\right) \bar{h}_{j, t}
$$

and

$$
P_{t}=\sum_{j=13}^{17} N_{j, t} I P_{j, t}
$$

Lastly, the government debt $(B)$ is given as,

$$
B_{t+1}-\left(1+r_{t}\right) B_{t}=G_{t}-R_{t} .
$$

\section{Foreign trade}

For completeness, we add the foreign sector account where the balance of payment is given by,

$$
T B_{t}=A_{t+1}^{f}-\left(1+r_{t}\right) A_{t}^{f},
$$

where $T B_{t}$ is net exports, and $A_{t}^{f}$ is foreign assets.

\section{Aggregation and market clearing}

The total weighted consumption, $C_{t}$, at each time period is given by,

$$
C_{t}=\sum_{j=1}^{17} \sum_{k=1}^{3} \operatorname{Pr}_{k} N_{j, t}\left(\bar{x}_{j, t}+\left(1-\left(1-\kappa_{t}\right)\left(1-o_{t}\right)\right) \bar{h}_{j, t}\right),
$$

where $\bar{x}_{j, t}$ is the average consumption expenditure on non-health goods and services of the $j^{\text {th }}$ age group and $\operatorname{Pr}_{k}$ is the share of the population according to their health insurance status (insured, uninsured, newly insured). Total labour is given by,

$$
L_{t}=\sum_{j=5}^{12}\left(1-u_{t}\right) N_{j, t} \bar{l}_{j, t}
$$

where $u_{t}$ is the unemployment rate and $\bar{l}_{j, t}$ is the average labour supplied by group $j$. Total households' assets, $A_{t}$, is given by, 
Table 1 Values of the model parameters in the baseline

\begin{tabular}{|c|c|}
\hline Parameter & Values \\
\hline \multicolumn{2}{|l|}{ Demographics } \\
\hline Population growth rate, $n_{t_{0}}$ & 0.156 \\
\hline Fertility rate, $f$ & 0.603 \\
\hline Survival rates, $q_{j}$ & $\in[0.65,0.99]$ \\
\hline Proportional change in the survival rate, $p_{j}$ & $\in\left[7 \times 10^{-5}, 4 \times 10^{-3}\right]$ \\
\hline Population shares, $\eta_{j, t_{0}}$ & $\in[0.005,0.15]$ \\
\hline \multicolumn{2}{|l|}{ Households preferences } \\
\hline Discount rate, $\beta$ & 0.985 \\
\hline Shares of healthcare expenditure, $\alpha_{j}$ & {$[0.028,0.135]$} \\
\hline Labour distribution parameter, $\mu_{j}$ & {$[0.00023,0.0007]$} \\
\hline Utility of elderly, $v_{j}$ & $\in\left[8 \times 10^{-4}, 1.1 \times 10^{-3}\right]$ \\
\hline Utility of elderly, $b_{j}$ & $-1 \times 10^{-6}$ \\
\hline \multicolumn{2}{|l|}{ Technology } \\
\hline Total factor productivity, $T$ & 3.34 \\
\hline Interest rate, $r$ & $0.2 \%$ \\
\hline The capital share, $\gamma$ & 0.25 \\
\hline Depreciation rate, $\delta$ & 0.43 \\
\hline \multicolumn{2}{|l|}{ UHC-oriented reform parameters } \\
\hline Premium rate, $\pi$ & $5 \%$ and $6 \%$ \\
\hline Copayment share, $\kappa$ & $15 \%$ \\
\hline Out-of-pocket payment share, $o$ & $40 \%$ \\
\hline $\begin{array}{l}\text { Fraction of premium rate at the firm } \\
\text { level, } \psi\end{array}$ & $30 \%$ \\
\hline Population coverage rate, $P r_{k}$ & $65 \%$ \\
\hline \multicolumn{2}{|l|}{ Policy parameters } \\
\hline Income tax, $\tau^{l}$ & $5 \%$ \\
\hline Tax on capital, $\tau^{k}$ & $6.7 \%$ \\
\hline Tax on consumption, $\tau^{c}$ & $16 \%$ \\
\hline $\begin{array}{l}\text { Employee contribution to the pension } \\
\text { system, } \tau^{P H}\end{array}$ & 0.07 \\
\hline $\begin{array}{l}\text { Government contribution to the pension } \\
\text { system, } \tau^{P G}\end{array}$ & 0.09 \\
\hline Unemployment rate, $u$ & $25.9 \%$ \\
\hline
\end{tabular}

$$
A_{t}=\sum_{j=5}^{17} N_{j, t} \bar{a}_{j, t}
$$

where $\bar{a}_{j, t}$ is the average assets for group $j$. The equilibrium requires that: (1) the capital market clears, $K_{t}=A_{t}+A_{t}^{f}-B_{t}$ and (2) aggregate supply equals aggregate demand, $Y_{t}=C_{t}+G_{t}+I_{t}+T B_{t}$.

\section{Calibration and settings}

To solve the model, the values of parameters, which are summarized in Table 1, are either calibrated on the benchmark data or set to their real values or to similar values reported in the literature. Demographic parameters for the baseline are calculated using the 2010-15 demographic surveys (PCBS, 2010, 2015). As shown in Table 1, the survival rate, $q_{j}$, which is calculated using life tables, is decreasing with age (e.g. $q_{17}=65 \%$ for elderly of the last age group). The value of the proportional rate of the survival rate, $p_{i}$, is found to be in the range $\left[7 \times 10^{-5}, 4 \times 10^{-3}\right]$. The main source of micro-data is the 2011 Palestinian Expenditures and Consumption Survey (PECS-2011) (PCBS, 2012a). The PECS is the main nationally representative cross-sectional survey that provides detailed information on health and non-health consumption expenditures of the Palestinian households. The parameters, $\alpha_{j}, \mu_{j}, v_{j}$ and $b_{j}$ are calibrated using the FOCs for heterogeneous households and the PECS2011. The initial endowments, $c_{j, 0}^{y}$ and $c_{j, 0}^{o}$, are first calculated for both young and elderly based on the PECS-2011, then the preference parameters are calculated for each household using the FOCs. Both $\alpha_{j}$ and $\mu_{j}$ are found to follow a U-shaped pattern with values higher for the female for $\alpha_{j}$ and values higher for the male for $\mu_{j}$. The discount utility parameter, $\beta$ is set at 0.985 as in Auerbach and Kotlikoff (1987).

Parameters pertaining to the macro-level are calibrated using macro data which are obtained from the Social Accounting Matrix (SAM-2011) (PCBS, 2012b) and the national accounts of 2015 (PCBS, 2016). The original SAM is composed of 16 disaggregate sectors for both the consumption and the production sides. Given our assumption of a single representative firm that produces the aggregate final output of the economy, the 16 disaggregate sectors are reduced to a single aggregate sector. The aggregate output, public and private investments, and aggregate labour supply are first calculated. Then, all technology parameters are calibrated to replicate the baseline macro data, where $T$ equals to $3.34, \gamma$ equals $25 \%$ reflecting a labour-intensive economy and $\delta$ equals to $43 \%$.

The parameters of the current GHI are calculated based on health reports and surveys published by the Ministry of Health (Palestinian Ministry of Health 2012, 2015; PCBS and MoH, 2013). We assume that the ratio of private health expenditures to public health expenditures is one-to-one, thus the individuals pay $50 \%$ of the total cost of healthcare. We decompose this into out-of-pocket payments $\left(o_{t}=40 \%\right)$, which is the direct health expenditures that households pay for uncovered healthcare and services, and copayment $\left(\kappa_{t}=15 \%\right)$ for covered healthcare and services. As for the health insurance contribution rate, each employed individual pays $5 \%$ of her income in addition to an amount equals to $\$ 1.5$ for each additional dependent. For the purpose of our analysis, we assume that, on average, young pay a contribution rate equals to $6 \%$, while elderly pay a lower rate which equals to $5 \%$. Finally, the baseline coverage rate of the population is $65 \%$. All policy parameters are set to their statutory values in 2015 , with input taxes of $\tau_{t}^{l}=5 \%$ and $\tau_{t}^{k}=6.7 \%$, and consumption tax, $\tau_{t}^{c}$, of $16 \%$. The pension system contributions are, $\tau_{t}^{P h}=7 \%$ and $\tau_{t}^{P G}=9 \%$. Lastly, the value of the unemployment rate is equal to $25.9 \%$ in 2015 .

We use Labor Force Survey (LFS-2015) to calculate wages, $w_{t_{0}}$ (PCBS, 2016). The LFS-2015 provides data on weekly work hours and monthly income by gender and economic activity. First, for each gender-economic activity group, $s$, we calculate average daily working hours as average weekly working hours divided by the number of working days per week which are assumed to be equal to 6 . Then we calculate wage per hour at the baseline, $w_{s, t_{0}}$, in USD as the average daily wage divided by average daily working hours. Using PECS, $l_{j_{0}, t_{0}}$ is, then, calculated as the total income divided by $w_{s, t_{0}}$. Thus, $l_{j_{0}, t_{0}}$ is the number of annual work hours. Then, the price of labour, $w_{t_{0}}$, is calculated as the weighted average of $w_{s, t_{0}}$ over all young. As regards simulation scenarios, we assume that the aggregate wage, $w_{t}$, of the single firm is adjusted following changes in individuals behaviour.

\section{Measuring fiscal sustainability and intergenerational inequality}

A variety of indicators has been proposed in the literature to assess debt (fiscal) sustainability, with little consensus on the optimal debt to Gross Domistic Product (GDP) threshold (Pescatori et al., 2014). For instance, the IMF and the World Bank suggest a framework where a country's debt-ceiling is determined by its institutional capacity (IMF and World Bank, 2012). Accordingly, the debt-ceiling can reach $49 \%, 62 \%$ and $75 \%$ of GDP for low-capacity, mediumcapacity and high-capacity countries, respectively. Adedeji et al. 
(2016) suggest a more prudent debt-level that is at least $10 \%$ lower than the debt-ceiling for low-income countries to account for adverse shocks and allow for some fiscal space. Given the limited institutional capacity of the Palestinian Authority and the high exposure to adverse shocks; e.g. political instability (IMF, 2016), we assess fiscal sustainability under alternative policy options using the prudent debt-level of $39 \%$ of GDP. Thus, if UHC generates additional debt, the optimal policy adjustment in terms of fiscal sustainability would be the one that generates adequate revenue to close the potential gap between the UHC-ridden debt and the prudent debt-level at a specific period of time.

However, such policy adjustment might not be deemed desirable in terms of intergenerational inequality. We, therefore, measure inequality across generations as the difference in the net UHC-burden borne by each generation at each time period. The net burden for generation $g, b_{t}^{g}$, is calculated for young and elderly, respectively, as,

$$
\begin{gathered}
b_{t}^{y}=\left[\left(h_{t}+h_{t}^{c}\right)+\pi_{t} w_{t} l_{t}+\Delta_{t}^{y}\right]-\left[\left(1-\kappa_{t}\right)\left(1-o_{t}\right)\left(h_{t}+h_{t}^{c}\right)\right] \\
b_{t}^{O}=\left[h_{t}+\pi_{t} I_{t}^{P}+\Delta_{t}^{o}\right]-\left[\left(1-\kappa_{t}\right)\left(1-o_{t}\right) h_{t}\right],
\end{gathered}
$$

where $\Delta$ represents the amount of the UHC-costs transferred to future generations. We, then, define a simple measure-the RIB of UHC-which compares the net burden borne by each generation (young vs elderly and current vs future) in the post- and pre-policy adjustment. The RIB is calculated for young-elderly and currentfuture generations, respectively, as

$$
R I B_{t}^{y o}=\frac{b_{t, p o s t}^{y}-b_{t, \text { post }}^{o}}{b_{t, \text { pre }}^{y}-b_{t, p \text { pre }}^{o}} \text { and } R I B_{t}^{f c}=\frac{b_{t, p o s t}^{y, f}-b_{t, p o s t}^{y, c}}{b_{t, \text { pre }}^{y, f}-b_{t, p r e}^{y, c}}
$$

Thus, a value greater than one indicates that the policy under consideration tends to widen the gap in the UHC-financing burden across generations. While the two measures can be used to assess intergenerational inequalities, an important distinction is worth highlighting. The $R I B_{t}^{y o}$ measures integrational transfers between young and elderly at a certain point of time, which may be considered as a measure of cross-subsidy stance of UHC. The RIB $B_{t}^{f c}$ captures the intergenerational transfers from current to future generations. A high value of $R I B_{t}^{f c}$ means that the future young bear the bulk of the policy adjustment burden. ${ }^{2}$

\section{Simulation scenarios}

Ensuring a fair UHC shall be considered in the context of fiscal sustainability. We, therefore, assess the impact of UHC on intergenerational inequality under alternative policy options that seek to restore fiscal sustainability within a specific timespan. The analysis involves two phases. The first is the 'UHC-implementation phase' (2015-20) during which the breadth and width of coverage are simultaneously expanded (from $65 \%$ to full coverage of population and from $50 \%$ to $70 \%$ of the total healthcare costs, ${ }^{3}$ respectively). Results from this microsimulation scenario are referred to as ' $S_{1}$ : benchmark scenario'. The second phase is the 'post-UHC-implementation', which spans over the first six periods following the UHC-implementation (2020-45). During this phase, the following policy options are considered and compared with $S_{1}$. These include: (1) rising income taxes, first, in a proportional $\left(S_{2}\right)$, and then, in a progressive manner $\left(S_{3}\right)$; (2) rising insurance premiums, first, in a proportional $\left(S_{4}\right)$, and then, in a progressive manner $\left(S_{5}\right)$ and (3) rising consumption tax $\left(S_{6}\right)$. We then consider an early policy adjustment that involves evaluating the effect of (1) both taxation and premiums policies in $a$ phased-manner starting from the UHC-implementation phase $\left(S_{7}\right.$ and $S_{8}$, respectively) and (2) a flat-rate increase in consumption taxes $\left(S_{9}\right)$.

\section{Results: the impact of UHC on fiscal sustainability and intergenerational inequality}

Results on the potential impact of UHC reform on intergenerational inequalities are examined in the context of fiscal sustainability (Table 2). As shown in Table 2, in the absence of any policy adjustment, the implementation of UHC (a parallel expansion of UHC breadth and width, scenario $S_{1}$ ) would have a sizeable impact on fiscal deficit (an increase by $134.4 \%$ and $37.3 \%$ in Period 1 and Period 7, respectively). As a result, the debt level would exceed the prudent debt-level by 13 points in Period 7 (52.8\% of GDP). Under such circumstances, the government may consider a policy adjustment through either debt finance (deferred taxation) or current taxation. We, therefore, consider first the impact of two alternative tax policies that are introduced in the post-UHC implementation phase (Period 3) to finance the UHC debt: a proportional increase in income tax rates from $5 \%$ to $10 \%$ (scenario $S_{2}$ ) and a progressive tax structure where tax rates increase with income quantiles as follows $6 \%, 8 \%, 10 \%, 11 \%$ and $12 \%$ (scenario $\left.S_{3}\right) .{ }^{4}$

As shown in Table 2, both tax policies can help close the gap between the UHC-ridden debt and the prudent debt-level in Period 7 (a debt-GDP ratio of $39 \%$ and $38 \%$ under $S_{2}$ and $S_{3}$, respectively). As far as the distribution of UHC-financing burden is concerned, the net burden that is borne by the young generations is, as expected, always higher than that borne by the elderly, regardless of the policy option. As compared with $S_{1}$ (no-policy adjustment), the RIB of UHC would be five times higher under both policies $\left(R I B_{t=7}^{y o}=5\right)$. It is, therefore, interesting to assess the impact of debt-financing policies on inequalities across young generations. Results on the $R I B_{t}^{f c}$ indicates that the RIB between future and current generation would be about seven times higher as compared with the benchmark.

The UHC burden can alternatively be financed through an augmentation in insurance premiums, which are borne by the active young population. Such policy is, first, examined in scenarios $S_{4}$, which involves a proportional increase in premiums from $6 \%$ to $11 \%$. Then, a progressive premiums scheme $(7 \%, 9 \%, 11 \%, 12 \%$ and $13 \%$ for income quintiles) is examined under $S_{5}$. Results, which are reported in Table 2, show that, unlike income tax policies, an equivalent increase in insurance premiums is not adequate to restore the debt-GDP ratio to the prudent level (a debt-GDP ratio of $43 \%$ ). As regards intergenerational inequality, similar trends to income tax policies are observed. However, smaller magnitudes are observed for the UHC RIB with the $R I B^{y o}$ and $R I B^{f c}$ being about four times and five times higher as compared with $S_{1}$. This indicates that future young generations would bear lower UHC burden under premium policies as compared with income tax policies.

In scenario $S_{6}$, a flat-rate increase of $5 \%$ is applied to consumption tax. This policy would reduce the UHC-ridden debt to $42 \%$ in Period 7 (three points greater than the prudent level). Similar to tax and premium policies, the net burden that is borne by the future generations is higher than that borne by current generations $\left(R I B_{t=7}^{f c}=4.3\right)$. However, unlike scenarios $S_{2}$ to $S_{5}$ where the young bear the bulk of the burden, under scenario $S_{6}$, the UHC-debt burden is borne by both future young and elderly resulting in a $R I B_{t=7}^{y o}$ of 2.3 .

The government may, alternatively, consider a phased-manner policy adjustment taking place in the first phase of UHCimplementation. We, therefore, examine in scenarios $S_{7}$ and $S_{8}$ the 


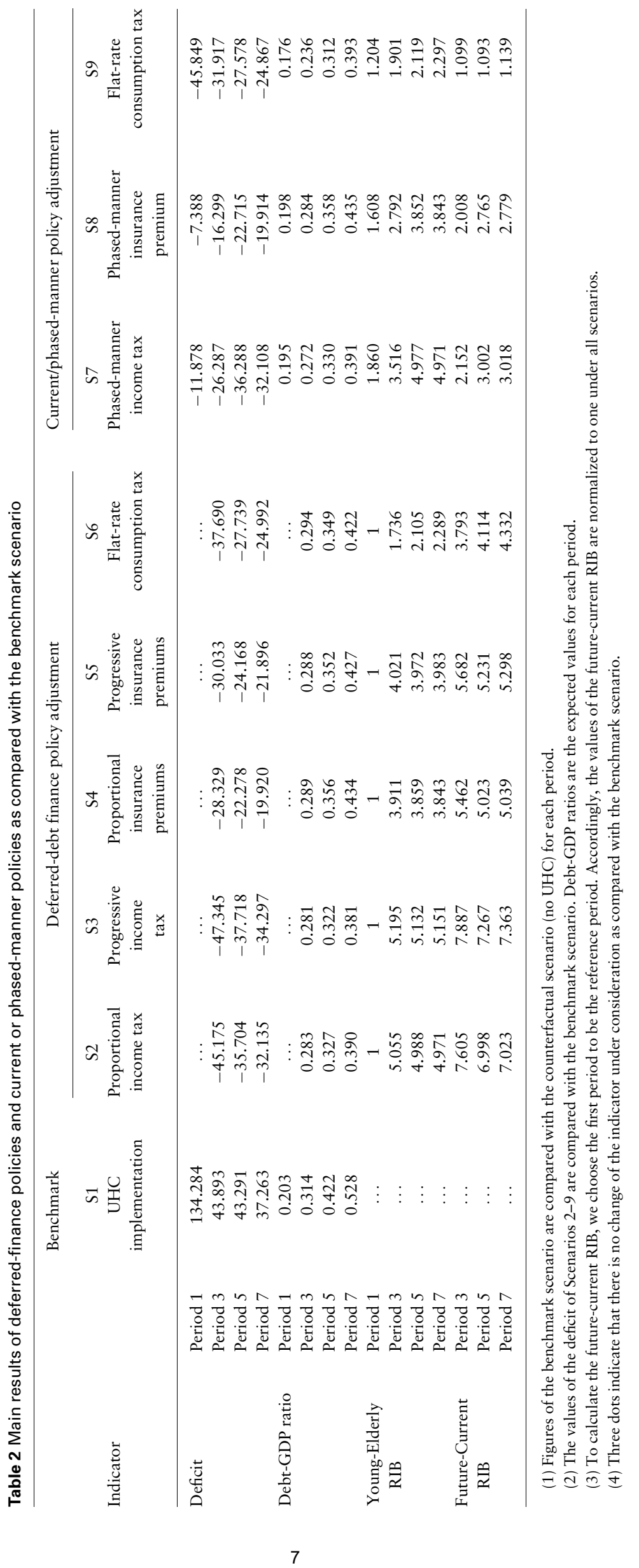


impact of a time-varying rates in income tax (from $6 \%$ in Period 1 to $10 \%$ in Periods 5 to 7 ) and in insurance premiums (from $7 \%$ in Period 1 to $11 \%$ in Periods 5 to 7). Results, which are reported in Table 2, show that the impact of the early phased-manner polices are generally similar to that observed when deferred-debt finance policies $\left(S_{2}\right.$ to $\left.S_{5}\right)$ are adopted. For instance, when implemented in a phased-manner, income tax policy would reduce the debt-GDP ratio to $39.1 \%$ as compared with $43.5 \%$ under insurance premium policy. Similar effects can also be observed as regards intergenerational inequalities between young and elderly (with the $R I B_{t=7}^{y o}$ being five times in $S_{7}$ and four times in $S_{8}$ higher of that of the benchmark scenario). However, inequality across future and current generations would be lower under scenarios $S_{7}$ and $S_{8}$ as compared with scenarios $S_{2}$ to and $S_{5}\left(R I B_{t=7}^{f c}=3.0\right.$ in $S_{7}$ and 2.8 in $\left.S_{8}\right)$.

Lastly, we consider the impact of a proportional increase of consumption tax by $5 \%$ undertaken in Period 1 (scenarios $S_{9}$ ). Results of this scenario are reported in Table 2. Expectedly, the gap of the UHC burden between young and elderly and future and current generations would not significantly increase as compared with other scenarios (with a $R I B_{t=7}^{y o}$ of 2.3 and $R I B_{t=7}^{f c}$ of 1.1 ). As regards fiscal sustainability, such policy appears to reduce the debt-GDP ratio to $39.3 \%$ in Period 7, which is comparable to that obtained for income tax adjustments but lower than that of premium adjustment policy.

\section{Discussion}

Results emerging from this article suggest that in the absence of any policy adjustment the simultaneous expansion of the breadth and width of UHC would blow up the fiscal deficit and the debt-GDP ratio (an increase by $37 \%$ and $65 \%$, respectively). This indicates that the UHC-fiscal stance is rather unsustainable in the long term, thus, calling for a policy adjustment to service the UHC debt. The question of which policy to choose requires an ex ante evaluation of the potential impact in terms of the magnitude of the revenues generated to service the UHC debt (the sustainability of the fiscal stance) and intergenerational inequality. Assessing the latter requires taking into account the policy impact on relative differences in the net burden borne by the young and the elderly as well as current and future generations in the post- and pre-policy adjustments. This is captured by the relative young-elderly and future-current incremental burden $\left(R I B^{y o}\right.$ and $R I B^{f_{c}}$, respectively) with a value greater than one indicating that the UHC-financing policy may exacerbate intergenerational inequalities. A number of interesting findings are worth discussing in light of the current debate on the sustainability of UHC reforms and its implications on intergenerational transfers.

Results on the first set of scenarios (deferred-debt finance) show that income tax policies may be preferred to other policies in terms of fiscal sustainability. Indeed, both proportional and progressive income taxes can restore the debt-GDP ratio at the prudent level through generating additional revenues to service the UHC debt. Nonetheless, increasing insurance premiums provide an alternative way to mobilize additional resources. In our model, however, such policy appears to generate less revenues compared with other policies. This is not surprising given that employers are assumed to bear $30 \%$ of insurance premiums, thus, higher insurance costs would negatively affect employment and, in turn, reduce revenues on labour-income tax. Accordingly, intergenerational transfers (from current to future generations) - as captured by the $R I B^{f c}$ - would be lower under such policy compared with income tax policies. As far as intergenerational transfers between young and elderly (i.e. crosssubsidy) are concerned, premium policies seem to be preferred over income tax as it is associated with a lower $R I B^{y o}$. Expectedly, implementing a consumption tax policy would spread the burden of the UHC debt over the wider population of future young and elderly (a fairly smaller $R I B^{y o}$ compared with other policies).

The deferred-debt policies considered above imply that the UHC debt is repaid in the long term by future generations. Such long-term borrowing involves intergenerational transfers, resulting in high values of $R I B^{f c}$ ranging between 4 and 7. Examining an early implementation of the above policies in a phased-manner indicates that the UHC debt is spread over current and future generations (as reflected by lower values of the $R I B^{f c}$ compared with those obtained under the deferred-debt policies as shown in Table 2). By comparing phased-manner policies in terms of their implications for fiscal sustainability, both income taxation and premium policies would have similar impact on the debt-GDP ratio as that observed under deferred-debt policies. By contrast, an early consumption taxation may be preferred over a deferred consumption taxation (as it decreases the debt-GDP ratio to $39 \%$ vs $42 \%$ ).

Although the framework proposed in this article can be adapted to assess the UHC implementation in other developing countries settings, some practical limitations are worth mentioning. These mainly relate to the simplifying assumption of a single representative profit-maximizing firm where the baseline value of the total output is equal to the total production of the disaggregate sectors underlying our single aggregate firm. Given the model assumptions, the potential impact of the simulation scenarios on the GDP would be captured via its respective components (i.e. household behaviour, the firm behaviour and the government budget). The rich specification of the OLG model accounts for the impact of alternative policy scenarios on heterogeneous households' preferences (viz. labour supply, health and non-health expenditures, wages, etc.). However, our model does not take into account the potential impact that the UHC may have on the sectoral reallocation and sectoral employment. A possible extension of the model may, thus, include a disaggregation of the production side to include the main sectors of the economy that are expected to be affected by the UHC policies in terms of labour, wages, etc. However, such a disaggregation analysis is beyond the scope of this article.

Another issue that is worth highlighting is related to the model assumptions on the working age cohort. In our model, we assume that the workforce cohort belongs to the young age group of 20-60 years. Although this assumption is context specific, one may opt for a wider age cohort of the workforce on the grounds that the UHC would increase access to healthcare, thus, improve population health capital and labour productivity. However, the impact of UHC on health capital requires a richer dataset on the health of heterogeneous agents, thus, it cannot be explicitly captured in our model. As expected, using our model, sensitivity analyses assuming a longer working age (15-65 years) showed that increasing labour supply would result in higher revenues from taxes and premiums. Accordingly, the debt-GDP ratio would be lower under the UHCfinancing policies considered in this article. Moreover, given a larger young cohort, the burden of the UHC would be distributed among a wider productive population. The gap of the UHC burden between young and elderly would be, therefore, lower under all scenarios. Results of the sensitivity analyses are available in an Appendix.

\section{Conclusion}

This article has examined ex ante the potential impact of UHC reform on intergenerational inequalities in view of fiscal sustainability 
using the case of Palestine. The questions of who bears the burden of UHC and whether the UHC-fiscal stance is sustainable in the long-term have been addressed using an OLG-CGE framework. We assessed and compared alternative strategies of financing the deficitridden UHC (viz. deferred-debt, current and phased-manner finance) and their implications on fiscal sustainability and intergenerational inequality. We ignored money-finance and bond-finance due to the absence of seigniorage in our context and only focused on fiscal policies (including income and consumption taxes and insurance premiums). Our results indicate that, in the absence of any policy adjustment, the implementation of UHC (even a gradual expansion in the breadth and width) would explode the fiscal deficit and the debt-GDP ratio. If the UHC debt is financed through deferred-debt policies, then the UHC-debt burden would fall on tomorrow's young generations. If instead, the debt is financed through current policy adjustments, then the UHC burden would fall on both today's and tomorrow's young generations unless the contractionary fiscal policy is released in the long-run (i.e. a temporary fiscal policy is used).

Results show that current or phased-manner policy adjustments involve lower intergenerational transfers as compared with the deferred-debt policy adjustments. From a social equity perspective, some may therefore argue in favour of current or phased-manner policy adjustment rather than deferred-debt. From an economic perspective, among the policy options we examined, the current consumption taxation policy emerged as the best policy option in terms of its impact on fiscal sustainability and intergenerational inequalities. It has been argued that in the context of developing countries, altering consumption tax might be easier than income-based policies (income tax and premiums) (Tanzi and Zee, 2000). This is because developing economies are characterized by a relatively high levels of informal employment (Schneider, 2002), which may hinder the fiscal capacity to generate adequate resources from income-based policies (Tanzi and Zee 2000; Ordóñez, 2014). However, from a policy perspective, the capacity of governments to raise additional revenues might be constrained in the short term (Gottret and Schieber, 2006; Kutzin et al., 2016). Under such circumstances, deferred-debt finance may be preferred. A situation in which policymakers may have to trade-off fiscal sustainability against intergenerational inequality. Such trade-offs may be more problematic in the context of low- and middle-income countries because, as mentioned at the outset, the choice of the current and future health financing policy will also depend on the relative size of each generation. In our case, although the share of the elderly is projected to increase by $68 \%$ in 2050 as compared with 2015 (reaching $8.8 \%$ in 2050), the young generations will form the majority of the polling population (about $44 \%$ in 2050 ). A policy option under which the young generations footing the bill of UHC may thus not be a 'vote winner' as the feasibility of a health financing mechanism also requires political acceptability.

\section{Notes}

1. We choose this functional formula of the utility function of health expenditure based on two facts: (1) utility is a non-linear function of health status (with $v>0$ and $b<0$ ) (Khwaja, $2010)$ and (2) health expenditure and health status are positively related. Accordingly, since there is no available information on health status, we assume that utility is a function of health expenditure and that the marginal utility of health expenditure is not always positive which is captured by the negative sign of the coefficient of the quadratic term.
2. These inequality measures are constructed in a way to measure whether changes in the counterfactual scenarios are magnified in the policy scenarios. Thus, these indices need not to satisfy the main properties of standard inequality measures.

3. In our model, the expansion of width is captured by a fall in the direct out-of-pocket payments share, $o_{t}$, from $40 \%$ to $17.65 \%$.

4. The increase of $5 \%$ in the income tax is not arbitrary here. In fact, simulation results of different tax rates, which are not reported here for sake of space, show that a $5 \%$ increase in tax would be adequate to restore fiscal sustainability within the timespan. The progressive income tax structure is thus chosen in a way such that additional total tax revenues equals revenues collected from the proportional tax. The same value is chosen for insurance premiums and consumption tax to allow comparison of different policies. Also of note, the choice of the timespan of 7 periods is not arbitrary as the impact of UHC on the fiscal deficit and debt starts to diminish at Period 7.

\section{Acknowledgements}

This work has been completed thanks to the funding of the A*MIDEX project (number ANR-11-IDEX-0001-02) funded by the French Government programme Investissements d'Avenir, managed by the French National Research Agency (ANR). This work was also supported by the French National Research Agency (Grants ANR-17-EURE-0020) and the European Union within the context of the EU-FEMISE (Forum Euro-Mediterranean of Institutes of Economics) project 'Support to economic research, studies and dialogue of the Euro-Mediterranean Partnership' (Agreement No. FEM4215). This work was also sponsored bythe Economic Research Forum (ERF) and has benefitted from both financial and intellectual support. The contents and recommendations do not necessarily reflect ERF's views.

Conflict of interest statement. We declare no coflicts of interest. .

Ethical approval. No ethical approval was required for this study.

\section{References}

Adedeji OS, Ahokpossi C, Battiati C, Farid M. 2016. A Probabilistic Approach to Fiscal Space and Prudent Debt Level: Application to Low-Income Developing Countries. IMF Working Paper, WP/16/163, Washington, D.C.

Andersen TM, Gestsson MH. 2016. Longevity, growth, and intergenerational equity: the deterministic case. Macroeconomic Dynamics 20: 985-1021.

Auerbach AJ, Gokhale J, Kotlikoff LJ. 1994. Generational accounting: a meaningful way to evaluate fiscal policy. Journal of Economic Perspectives 8: 73-94.

Auerbach AJ, Kotlikoff LJ. 1987. Dynamic Fiscal Policy. Vol. 11. Cambridge: Cambridge University Press.

Balassone F, Cunha J, Langenus G et al. 2008. Fiscal sustainability and policy implications for the euro area. Banque de France NER, 225.

Bassetto M. 2008. Political economy of taxation in an overlapping-generations economy. Review of Economic Dynamics 11: $18-43$.

Creedy J, Guest R. 2008. Changes in the taxation of private pensions: macroeconomic and welfare effects. Journal of Policy Modeling 30: 693-712.

Dye C, Reeder JC, Terry RF. 2013. Research for Universal Health Coverage. American Association for the Advancement of Science, Washington, D.C.

Gottret PE, Schieber G. 2006. Health Financing Revisited: A Practitioner's Guide. World Bank Publications, Washington, D.C.

Grundy E. 2005. Reciprocity in relationships: socio-economic and health influences on intergenerational exchanges between third age parents and their adult children in Great Britain. The British Journal of Sociology 56: $233-55$. 
Guest R. 2008. Smoothing the fiscal costs of population ageing in Australia: effects on intergenerational equity and social welfare. The Economic Record 84: 177-92.

Halliday TJ, He H, Ning L, Zhang H. 2019. Health investment over the life-cycle. Macroeconomic Dynamics 23: 178-38.

Heller P. 2006. The prospects of creating 'fiscal space' for the health sector. Health Policy and Planning 21: 75-9.

International Monetary Fund (IMF). 2016. West Bank AND Gaza: Report to the Ad Hoc Liaison Committee. IMF, Washington, D.C., 5 April.

International Monetary Fund (IMF) and World Bank. 2012. Revisiting the Debt Sustainability Framework for Low-Income Countries. Washington, D.C. https://www.imf.org/external/np/pp/eng/2012/011212.pdf.

Khwaja A. 2010. Estimating willingness to pay for medicare using a dynamic life-cycle model of demand for health insurance. Journal of Econometrics 156: 130-47.

Kutzin J, Yip W, Cashin C. 2016. Alternative financing strategies for universal health coverage. In: Scheffler RM (ed). World Scientific Handbook of Global Health Economics and Public Policy: Volume 1: The Economics of Health and Health Systems. Singapore: World Scientific Publishing Co Pte Ltd, 267-309.

Lagomarsino G, Garabrant A, Adyas A, Muga R, Otoo N. 2012. Moving towards universal health coverage: health insurance reforms in nine developing countries in Africa and Asia. The Lancet 380: 933-43.

Palestinian Central Bureau of Statistics (PCBS). 2010. Palestinians at the End of 2010. Ramallah, Palestine: Palestinian Central Bureau of Statistics.

Palestinian Central Bureau of Statistics (PCBS). 2012a. Palestinian Expenditure and Consumption Survey 2011. Ramallah, Palestine: Palestinian Central Bureau of Statistics.

Palestinian Central Bureau of Statistics (PCBS). 2012b. The Social Accounting Matrix 2011. Ramallah, Palestine: Palestinian Central Bureau of Statistics.

Palestinian Central Bureau of Statistics (PCBS). 2015. Palestinians at the End of 2015. Ramallah, Palestine: Palestinian Central Bureau of Statistics.

Palestinian Central Bureau of Statistics (PCBS). 2016. The Labor Force Survey in Palestine 2015. Ramallah, Palestine: Palestinian Central Bureau of Statistics.
Palestinian Central Bureau of Statistics (PCBS), Ministry of Health (MoH). 2013. National Health Accounts. Palestinian Central Bureau of Statistics and Ministry of Health, Ramallah, Palestine.

Palestinian Ministry of Health (MoH). 2012. Annual Health Reports, 2011. Ramallah, Ministry of Health, Health Information Centre.

Palestinian Ministry of Health (MoH). 2015. Health Report Mid-Year 2015. Ramallah, Ministry of Health, Health Information Centre.

Pescatori A, Sandri D, Simon J. 2014. Debt and Growth: Is There a Magic Threshold? IMF Working Paper WP/14/34, Washington, D.C.

Schneider F. 2002. Size and measurement of the informal economy in 110 countries. In: Workshop of Australian National Tax Centre, (vol. 17). Canberra: ANU.

Smith SK, Tayman J, Swanson DA. 2006. State and Local Population Projections: Methodology and Analysis. Springer Science \& Business Media, Berlin.

Somanathan A, Tandon A, Dao HL, Hurt KL, Fuenzalida-Puelma HL. 2014. Moving toward Universal Coverage of Social Health Insurance in Vietnam: Assessment and Options. World Bank Publications, Washington, D.C.

Tanzi V, Zee HH. 2000. Tax policy for emerging markets: developing countries. National Tax Journal 53: 299-322.

Tokuoka K. 2012. Intergenerational Implications of Fiscal Consolidation in Japan. IMF Working Paper No. 12/197, Washington, D.C.

Tovar JA, Urdinola BP. 2014. Inequality in national inter-generational transfers: evidence from Colombia. International Advances in Economic Research 20: 167-87.

Van Kippersluis H, Van Ourti T, O’Donnell O, Van Doorslaer E. 2009. Health and income across the life cycle and generations in Europe. Journal of Health Economics 28: 818-30.

Wickens M. 2012. Macroeconomic Theory: A Dynamic General Equilibrium Approach. Princeton University Press, Princeton.

World Bank. 2008. West Bank and Gaza Strip Health Policy Report: Reforming Prudently under Pressure. World Bank, Washington, D.C.

World Health Organization (WHO). 2017. WHO Symposium on Health Financing for UHC Public Financing for UHC: Towards Implementation. Montreux, Switzerland (No. WHO/HIS/HGF/HFWorkingPaper/18.1). World Health Organization. 


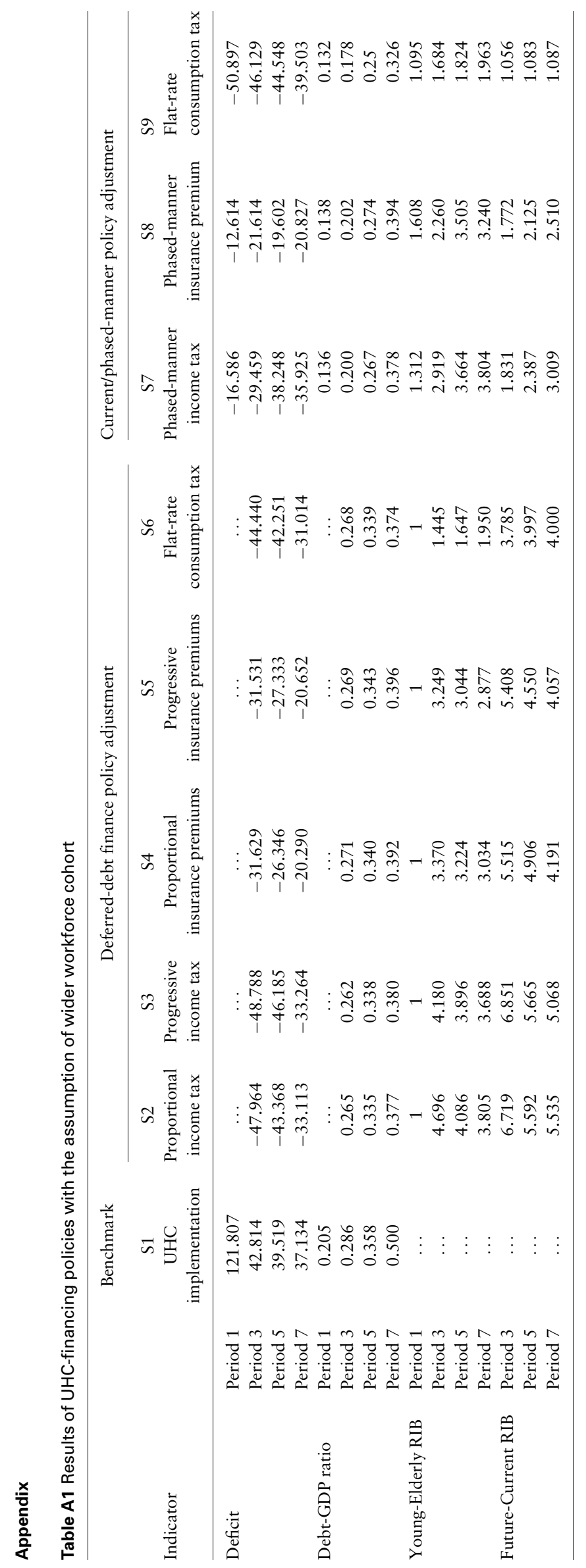

